\title{
Cardiac magnetic resonance imaging of primary cardiac tumors
}

\author{
Xiaodan Li ${ }^{1}$, Yan Chen ${ }^{1}$, Jiayi Liu ${ }^{1}$, Lei Xu' ${ }^{1}$, Yu Li ${ }^{1}$, Dongting Liu ${ }^{1}$, Zhonghua Sun ${ }^{2}$, Zhaoying Wen ${ }^{1}$ \\ ${ }^{1}$ Department of Radiology, Beijing Anzhen Hospital, Capital Medical University, Beijing 100029, China; ${ }^{2}$ Discipline of Medical Radiation Sciences, \\ School of Molecular and Life Sciences, Curtin University, Perth, Australia
}

Correspondence to: Zhaoying Wen. Department of Radiology, Beijing Anzhen Hospital, Capital Medical University, No. 2 Anzhen Rd., Chaoyang District, Beijing 100029, China. Email: wenzhaoying11@163.com.

\begin{abstract}
Cardiac magnetic resonance (CMR) offers superior advantages in cardiac imaging due to supplying a greater field of view, excellent soft-tissue imaging, and multiplanar imaging capabilities. CMR imaging can evaluate the characteristics of cardiac tumors by visualizing the relationship between the tumor and surrounding tissues, and plays a vital role in assisting the formulation of the surgical plan, the assessment of tumor progression, and the monitoring of postoperative tumor recurrence and metastasis. In this review, we present the clinical manifestations and imaging features of different cardiac tumors. The superior performance of CMR in preoperative diagnosis, surgical treatment, and postoperative follow-up of patients with heart tumors are also highlighted.
\end{abstract}

Keywords: Primary cardiac tumors; cardiac magnetic resonance (CMR); thrombus; cardiac myxoma; angiosarcoma

Submitted Jul 11, 2019. Accepted for publication Nov 14, 2019.

doi: 10.21037 /qims.2019.11.13

View this article at: http://dx.doi.org/10.21037/qims.2019.11.13

\section{Introduction}

Cardiac masses include tumors and non-neoplastic lesions. Cardiac tumors are characterized by masses in the cardiac cavity, myocardium, or pericardium, which can involve valves or papillary muscles. In 2015, the World Health Organization (WHO) released a new histologic classification of primary cardiac tumors, which are divided into benign tumors, uncertain biological behavior tumors, germ cell tumors, and malignant tumors (1). Primary cardiac tumors are rare, with the incidence rate being less than $0.3 \%$ (2), of which about $75 \%$ of primary heart tumors are benign, and about $25 \%$ are malignant (3). The most common primary cardiac tumor is a benign cardiac myxoma, accounting for about $50 \%$ of cases. Rhabdomyoma is the most common primary benign tumor of the heart in children. Primary malignant cardiac tumors include sarcoma and lymphoma. Sarcomas are the most common malignant primary cardiac tumors accounting for about $95 \%$ of cases, while lymphoma accounts for about $5 \%$ of malignant primary cardiac tumors. Metastases are 20-40 times more common than primary cardiac tumors (3). The most frequent malignant tumors that migrate to the heart are those of lung cancer, breast cancer, lymphoma, and malignant melanoma (4). An inflammatory myofibroblastic tumor (IMT) is rarely found to be involved in the heart.

Intracardiac thrombus is a non-neoplastic lesion commonly found in clinical practice. General X-ray and computed tomography (CT) can provide significant morphological information, but the qualitative diagnosis and assessment for cardiac tumors of these examinations are limited. Although echocardiography is often the first choice in the diagnosis of cardiac tumors, it is an operatordependent modality, which, to some extent, restricts its diagnostic accuracy. By virtue of its good spatial resolution, the capability to acquire images in multi-plane or multidirection, and favorable tissue characterization (5), cardiac magnetic resonance (CMR) is a preferred method for the comprehensive assessment of cardiac tumors, and can help in differentiating between benign and malignant tumors (6). CMR opens up a new way of exploring the tissue components of various cardiac tumors and can aid 
Table 1 Application of CMR scanning technology

\begin{tabular}{lll}
\hline Images & Sequences & Advantages \\
\hline Cine-MR imaging & $\begin{array}{l}\text { "Bright blood" balanced SSFP sequences; } \\
\text { ECG gated, breath-held }\end{array}$ & $\begin{array}{l}\text { Evaluate the location, morphology, extent, border, } \\
\text { mobility of cardiac masses, dilatation and contractility } \\
\text { of heart, valvular dysfunction, pericardial lesion, extra- } \\
\text { cardiac involvement }\end{array}$ \\
T1WI or T2WI STIR sequences & "Black blood" balanced SSFP sequences; Diagnosis of fat-bearing masses \\
& ECG gated, breath-held & \\
T2WI & "Black blood" balanced SSFP sequences; Detecting regions of edema and cystic change \\
& ECG gated, breath-held & \\
First-pass perfusion & Saturation recovery; ECG gated, breath-held & Mass vascularity, tissue characterization \\
Late gadolinium enhancement & T1w, inversion recovery, TI time adjusted to & Mass vascularity, tissue characterization \\
(LGE) & null normal myocardium, ECG gated, breath- & \\
held & T1w, inversion recovery, fixed TI 600 ms, ECG Differentiate thrombus from tumor \\
(20 min post contrast) & gated, breath-held
\end{tabular}

CMR, cardiac magnetic resonance; T1WI, T1-weighted imaging; T2WI, T2-weighted imaging; STIR, short time inversion recovery; SSFP, steady-state free precession; ECG, electrocardiogram; TI, inversion time.

in guiding clinical diagnosis and treatment. Its enhanced scanning can effectively identify tumors and thrombus (7). Other non-neoplastic lesions can also be assessed by CMR, including lipomatous hypertrophy of the interatrial septum, caseous calcification of the mitral valve, prominent crista terminalis, giant coronary aneurysm, large hiatal hernia, elongated Chiari network, prominent Eustachian valve, and prominent pericardial fat (8). This review provides an overview of the applications of CMR in cardiac tumors, with a focus on imaging appearances. Table 1 shows the advantages of different CMR imaging sequences in the diagnosis of cardiac tumors (9).

\section{CMR diagnosis of non-neoplastic lesions}

\section{Cardiac thrombus}

Thrombus is one of the most common factors of intracardiac mass and a frequent differential diagnosis associated with cardiac tumors. Thrombus usually occurs in the left atrium and is related to atrial fibrillation or mitral valve disease. It can also be seen in the left ventricle with a reduced ejection fraction due to severe systolic dysfunction after myocardial infarction (10) (Figure 1). The thrombus often adheres to the infarcted or scarred myocardium. The right atrial thrombus can be seen when there is a central venous catheter. Benign cardiac tumors can be treated with surgical resection; however, appropriate anticoagulant therapy for thrombus can be resolved. Anticoagulant therapy in the presence of cardiac tumors might increase the risk of hemorrhage, so the diagnosis of thrombus is particularly significant. The thrombus in cine MR image can show as iso- or hypointense. Acute thrombus usually is hyperintense on T1- and T2-weighted imaging due to oxygenated hemoglobin. Hemoglobin is transformed into methemoglobin in subacute thrombus, leading it to be hyperintense on T1-weighted imaging and hypointense on T2-weighted imaging (11). In the chronic period, the thrombus is replaced by fibrous tissue. As the fibrosis content increases, the thrombus is characterized by hypointensity on T1- and T2-weighted imaging (12).

It has been shown that the thrombus does not uptake the gadolinium contrast medium, and there is no enhancement on early gadolinium enhancement (EGE) and late gadolinium enhancement (LGE) imaging. Peripheral enhancement can be occasionally seen in chronic organic thrombus due to fibrotic components (13). In addition, the incidence of thrombus increases with decreased left ventricular ejection fraction, increased myocardial scarring, and ischemic myocardial changes. Therefore, CMR imaging has a certain value in the diagnosis of coronary heart disease when suspected thrombus. Meanwhile, studies have shown that myocardial scar is an independent risk factor for thrombus. CMR can show necrosis, fresh hemorrhage, or calcification within the thrombus. 

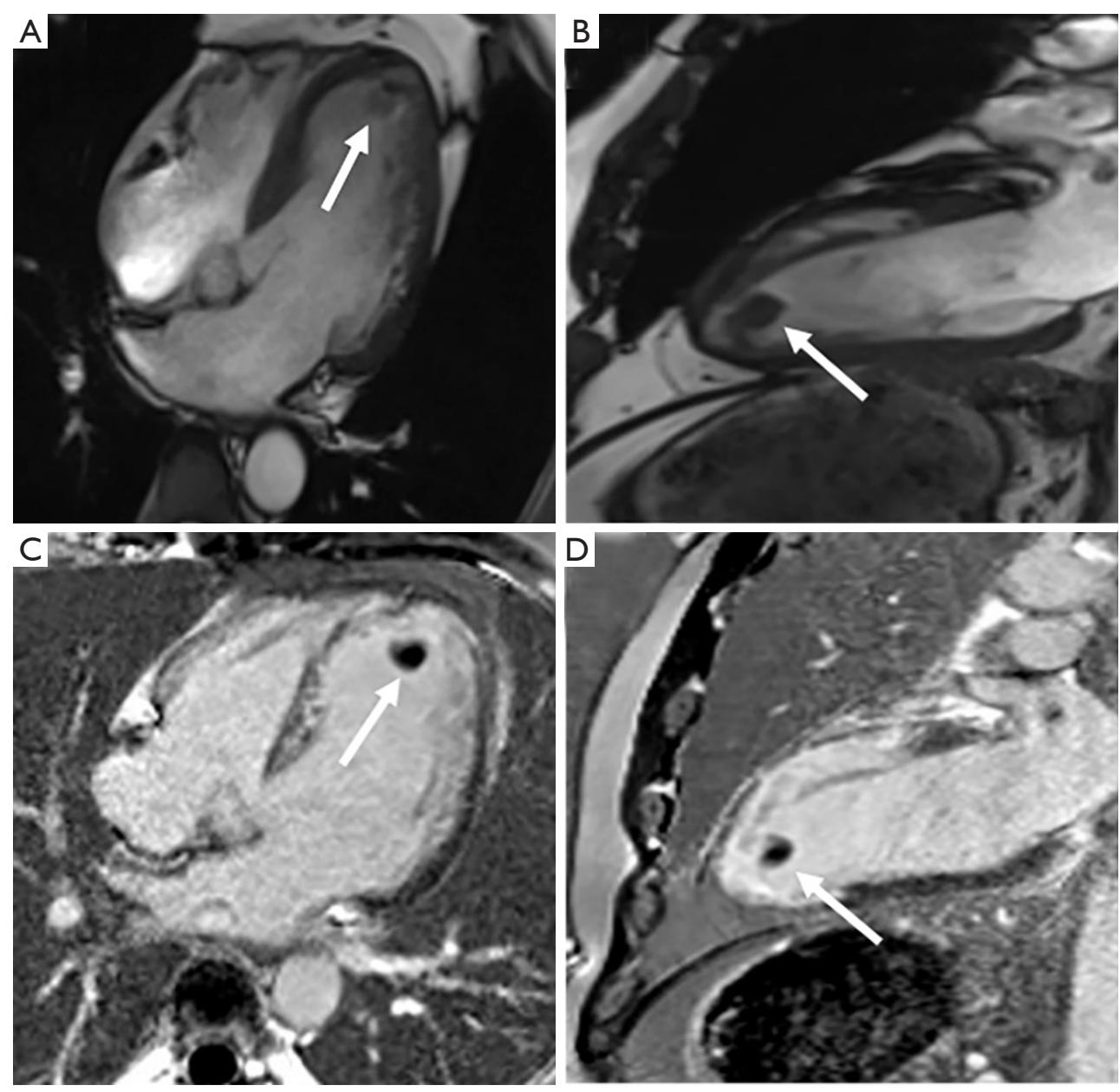

Figure 1 A 56-year-old male with old myocardial infarction after percutaneous coronary intervention (PCI) stenting for coronary heart disease is diagnosed with left ventricle thrombus. (A,B) A hypointense mass is seen at the left ventricular apex on the cine images with a welldefined boundary (arrow). (C,D) There is no enhancement of the mass on LGE (arrows), which is consistent with thrombus appearance.

\section{Pericardial cyst}

The pericardial cyst is a benign congenital effusion structure, and is usually located at the right cardio-phrenic angle. Most cases of this cyst are accidental findings, but if very large, they can compress adjacent structures and cause clinical symptoms. The pericardial cyst has a well-defined edge and a homogeneous fluid signal. It frequently shows as hypointense and hyperintense on T1- and T2-weighted images, respectively. There is no delayed enhancement on LGE (Figure 2) (4). Pericardial cysts and the thrombus are summarized in Table 2.

\section{Imaging diagnosis of benign cardiac tumor}

\section{Myxoma}

Cardiac myxoma is the most common benign cardiac tumor, accounting for about $50 \%$ of total cases (14). Myxoma is a benign glial tumor composed of endothelial cells, smooth muscle cells, and pluripotent mesenchymal cells. Tumors are generally located in the left atrium (75\%), right atrium $(23 \%)$, or left ventricle (2\%), and frequently have narrow stalk attached to the atrial septum, typically in the oval fossa (15) (Figure 3). They are found in the 30-60 age group and frequently solitary with a size of 

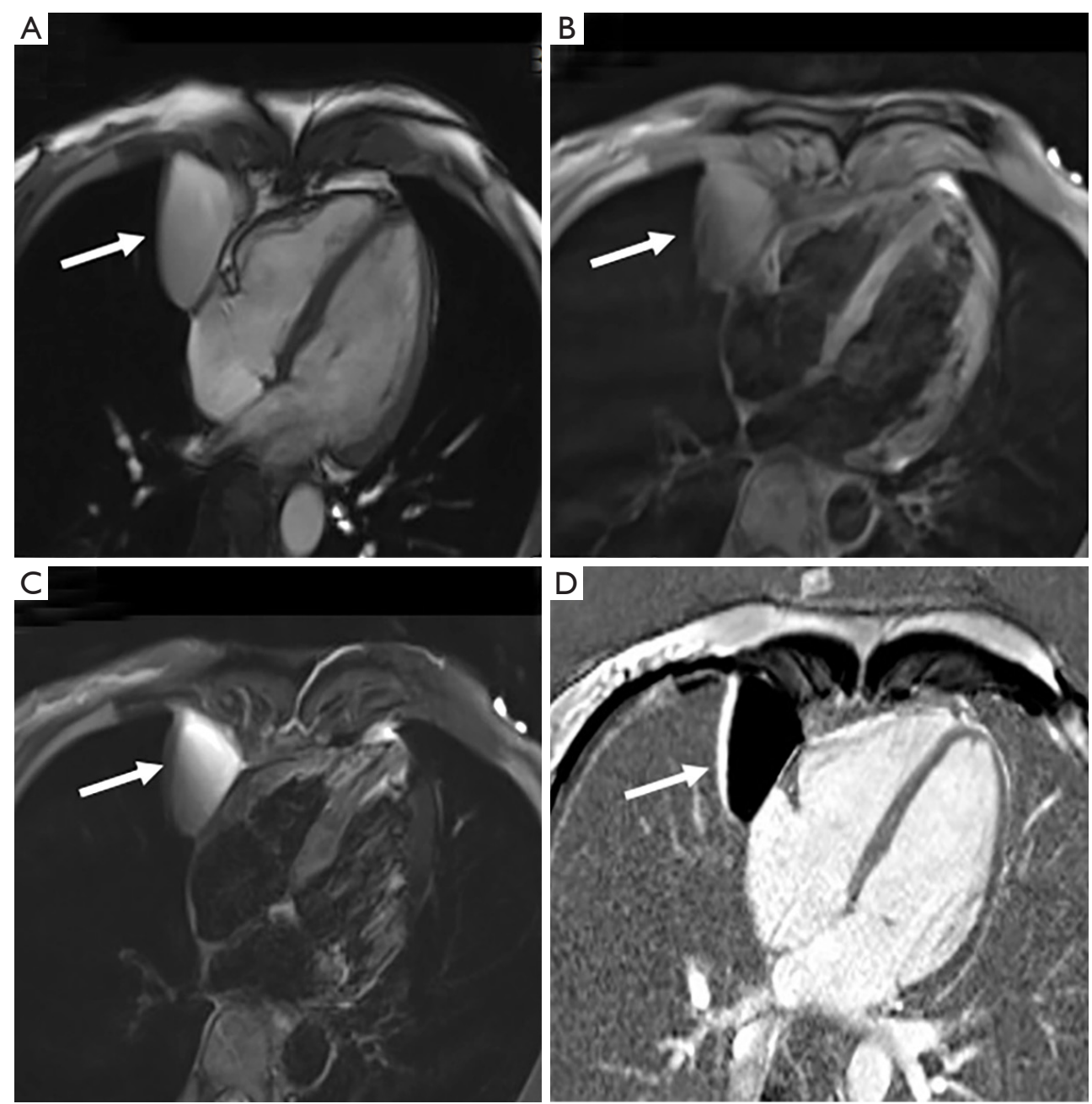

Figure 2 A 30-year-old woman was diagnosed with a pericardial cyst. (A) The cine image shows a well-delimited hyperintense cystic lesion at a right cardio-phrenic angle with no effects on cardiac contractility (arrow). (B,C) The cyst shows hypointense on T1-weighted imaging (arrow), and hyperintense on T2-weighted imaging (arrow). (D) No enhancement is found after contrast agent administration (arrow).

4-8 cm (Figure 4). The incidence of familial myxoma is below $10 \%$; it is an autosomal dominant genetic disease with an early age of onset and a recurrence rate of $12-25 \%$ after surgery. Myxoma, if large enough, may be pushed into the mitral valve orifice during diastole, leading to atrioventricular valve obstruction. Myxomatosis of the heart or other organs with skin pigmentation and endocrine neoplasms is known as Carney syndrome (16). Systemic embolization is the main complication of left atrial myxoma. Its heterogeneous enhancement and the vessels in the mass distinguish it from intracavity thrombus. CT can show calcification in the mass. The cine MRI images depict a mobile lesion in the cardiac cavity, and myxoma is typically manifested as isointense or heterogeneous intense on
T1-weighted imaging and hyperintense or heterogeneous intense on T2-weighted imaging. Due to hemosiderin deposition, T1-weighted imaging sometimes presents a hypointense signal.

Coronary CT angiography shows the supplying artery of left atrial myxoma originating from the left circumflex coronary artery, the right coronary artery, or the left posterior ventricular branch. Surgical excision is an effective treatment to prevent systemic embolism and cardiovascular complications (17). Myxoma patients have a good prognosis, with a recurrence rate between $1 \%$ and $5 \%$. Causes of myxoma recurrence include incomplete resection, intraoperative tumor implantation, and multifocal tumors. During the follow-up, periodical echocardiographic 
inspection is crucial for the monitoring of response to treatment and the recurrence of lesions.

\section{Papillary fibroelastoma}

Papillary fibroelastoma is the second most common benign cardiac tumor, accounting for about $16 \%$ of cases (4). It commonly occurs in $60-80$-year-olds, and there is no difference between males and females. Tumors originate from the endocardium and consist of myxoid connective tissue covered by the endothelium. Tumors are usually solitary and less than $2 \mathrm{~cm}$ in size (15). More than $80 \%$ of tumors originate from the valve away from the valvular free edge, which is the most common valve tumor, and can be found located on the aortic valve (29\%) (Figure 5), mitral valve (25\%), tricuspid valve (17\%), and pulmonary valve (13\%) (17). The common sites of masses are the left atrial side of the mitral valve and the aortic side of the aortic valve. Fewer tumors may occur on the non-valvular endocardial surface, which accounts for $16 \%$ of cases. Fibroelastoma is considered a hamartoma or a response to trauma from a pathophysiology point of view, and $30 \%$ of fibroelastoma patients are asymptomatic and without valve dysfunction (18). In severe cases, systemic clinical symptoms may include stroke, transient ischemic attack, myocardial infarction, and pulmonary embolism. CMR has become the preferred method to evaluate fibroelastoma. Typical findings are small, highly active valve masses, with short, thin stalk presenting hypointense on cine CMR images, isointense on T1-weighted, and isointense on T2-weighted imaging. The main differential diagnosis includes valvular vegetation and thrombus. Contrast enhancement can easily identify thrombus. Mitral valve vegetations usually occur in patients with suspected infective endocarditis and destroy the valve, while fibroelastoma is rarely associated with functional impairment of the valve. Surgical resection is only performed in patients with tumors of a large volume $(>1 \mathrm{~cm})$, high activity, obvious clinical symptoms, and that are located in the left heart (19).

\section{Rhabdomyoma}

Rhabdomyoma, which is rare in adults, is the most common heart tumor in children, accounting for about $90 \%$ of the primary benign heart tumors in this age group, with $75 \%$ occurring in children under 1 year of age. Most lesions tend to regress naturally and do not require surgical treatment (20). The presence of inflow or outflow tract 

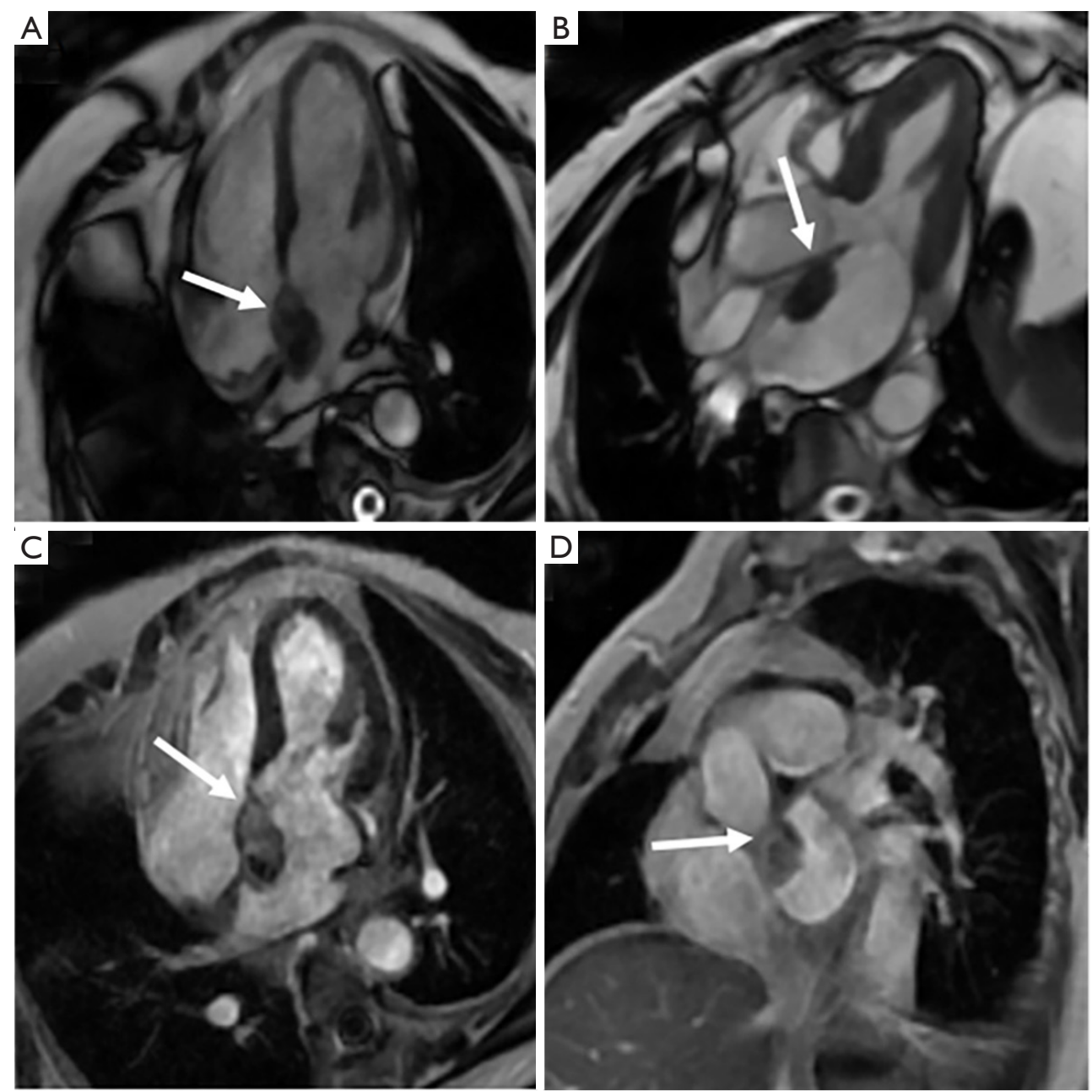

Figure 3 A 62-year-old female diagnosed with myxoma. (A,B) CMR cine images show a well-defined tumor near the oval fossa of the atrial septum with hypointense (arrows). (C,D) Heterogeneous enhancement is seen within the mass on LGE (arrows). CMR, cardiac magnetic resonance; LGE, late gadolinium enhancement.

obstruction and arrhythmias require excision (21). Rhabdomyomas are hamartoma nodules with firm margins, characterized histologically by an abnormal mix of muscle cells with large glycogen vacuoles that can occur anywhere in the heart and pericardium (17). Rhabdomyomas often present as multiple masses in the ventricular wall, and more commonly in the left ventricle than in the right ventricle. Hemorrhage and calcification are uncommon. On ultrasound, cardiac rhabdomyomas usually present as small, lobulated, uniform, hyperechoic masses that originate from the myocardium or ventricular septum. CMR cine images show focal ventricular wall motion abnormalities, with iso- or slightly hyperintense on T1weighted imaging and usually hyperintense on T2-weighted imaging, without significant enhancement after contrast medium administration (22). Myocardial rhabdomyomatosis is a rare disease characterized by myocardial infiltration, presenting as diffuse myocardial thickening that can cause cardiomyopathy.

\section{Hemangioma}

Cardiac hemangioma is a rare benign vascular lesion, accounting for $5 \%$ to $10 \%$ of primary cardiac tumors (23). Patients of all ages can develop the disease. Most of the patients are asymptomatic, and some of them show palpitations, arrhythmias, and cerebral embolism (24). The size of cardiac hemangioma can range from $1-8 \mathrm{~cm}$. 

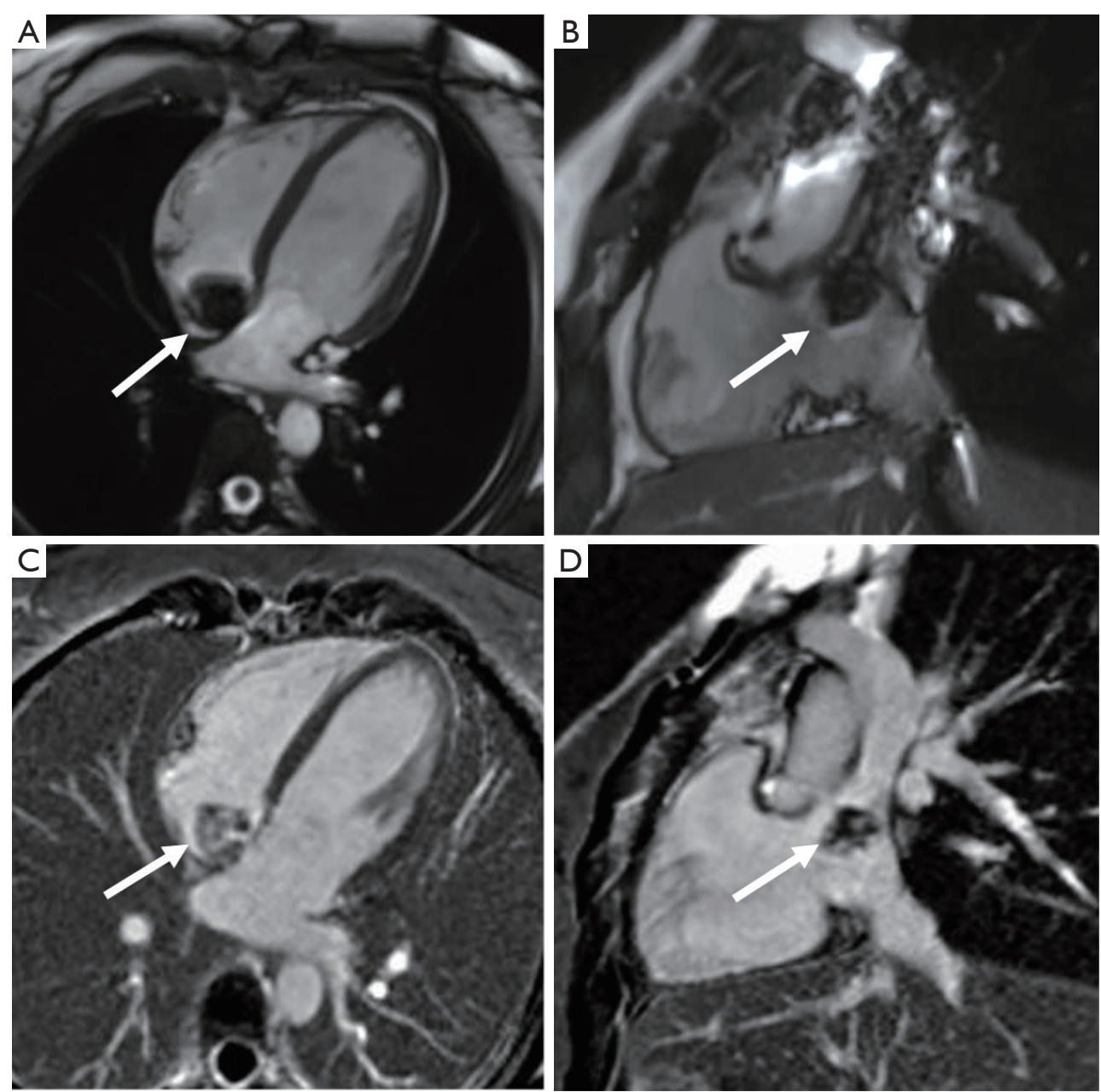

Figure 4 A 37-year-old female with chest tightness diagnosed with myxoma. (A,B) CMR cine images show the mass in the right atrium near the atrial septum with a circular shape and a distinct margin (arrows). (C,D) The mass has heterogeneous enhancement on LGE (arrows). CMR, cardiac magnetic resonance; LGE, late gadolinium enhancement.

They can occur in any cardiac cavity, with neonatal hemangiomas usually occurring in the right atrium, but most of them are located in the ventricle, especially in the lateral wall of the left ventricle (Figure 6), the anterior wall of the right ventricle, and the interventricular septum (25). Histologically, this lesion can be divided into cavernous hemangioma, capillary hemangioma, or arteriovenous hemangioma. On CMR images, the hemangioma shows a clear, movable, slightly hypointense mass in the cardiac cavity. Due to the slow blood flow, the hemangioma shows as isointense on T1-weighted imaging, hyperintense on $\mathrm{T} 2$-weighted imaging, and hyperintense on fat-suppressed images. There is significant heterogeneous prolonged enhancement after injection of contrast medium, but there could also be heterogeneous areas due to calcification or fiber septum (26).

\section{Fibroma}

Fibromas are the third most common primary cardiac tumors in children after rhabdomyomas and teratomas (21), and approximately one-third of patients are detected incidentally. Fibromas are congenital tumors arising from the septal or left ventricular free wall and are usually solitary and clearly demarcated from the adjacent myocardium. Fibromas frequently contain fibroblasts, collagen, and focal calcification. Hemorrhage, necrosis, and cystic degeneration are rare in tumors. Tumor resection is usually 

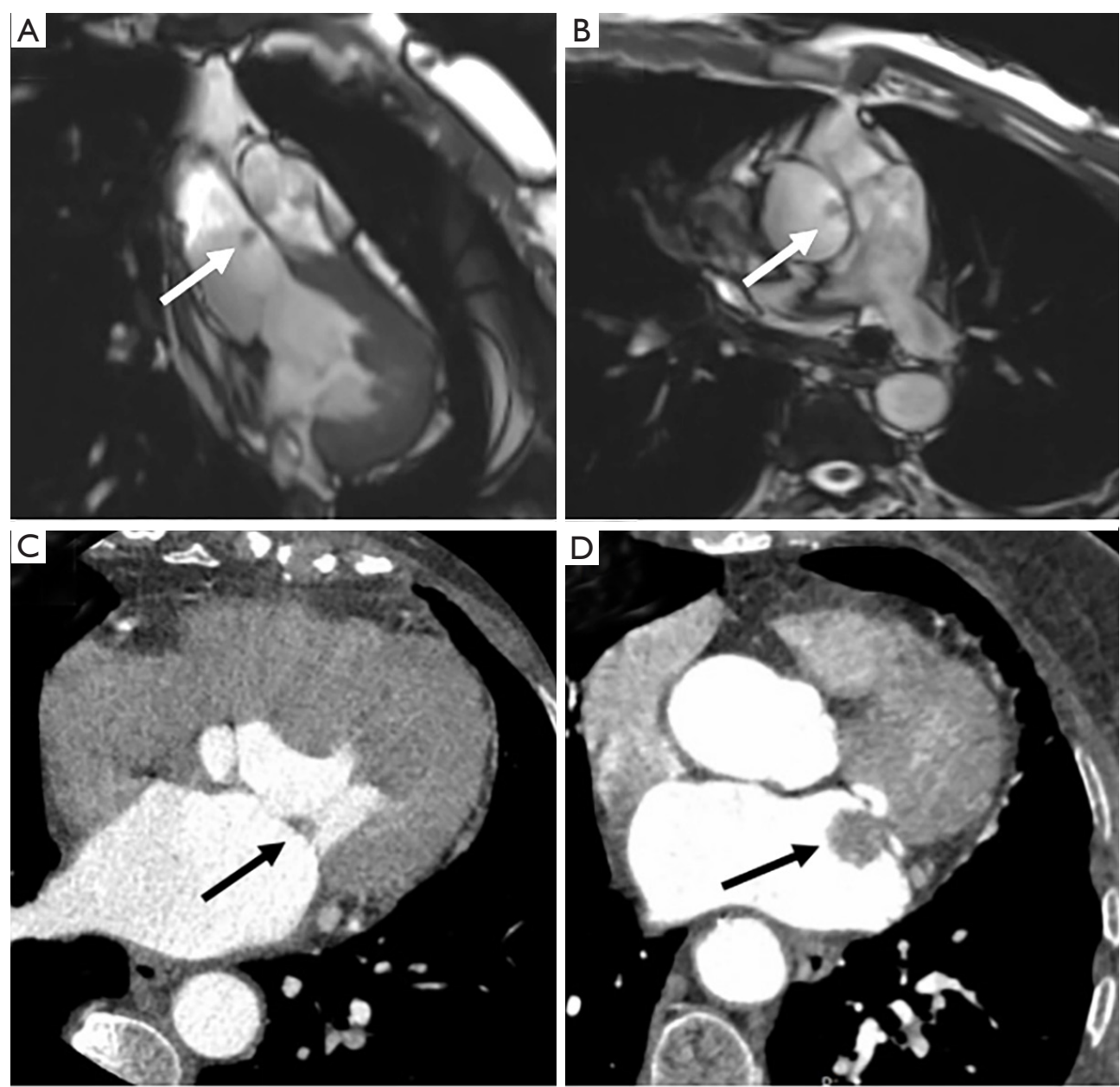

Figure 5 A 55-year-old male is diagnosed with aortic valve fibroelastoma. (A,B) A small nodular hypointense of the aortic valve in the cine images (arrows). (C) Coronary CT angiography shows fibroelastoma on the left ventricular side of the posterior mitral valve in a 62-year-old female (black arrow). (D) Coronary CT angiography shows fibroelastoma on the left atrial side of the posterior mitral valve in a 66-year-old female (black arrow).

needed because of the enormous size of the tumor (mean size $5 \mathrm{~cm}$ ), which may lead to heart failure, arrhythmia, or sudden death. Cardiac fibromas may be associated with Gorlin syndrome, an autosomal dominant disease characterized by basal cell carcinoma and odontogenic keratocyst (27). Fibromas often present as iso-hypointense mass on cine images, isointense on T1-weighted imaging, and hypointense on T2-weighted imaging. The perfusion is decreased and has significantly homogeneous delayed enhancement on LGE (Figure 7) (28).

\section{Lipoma}

Cardiac lipomas are benign tumors of the heart composed of mature adipose tissue, and accounting for about $16 \%$ of lesions. Lipomas are well-bordered, homogeneous masses with a complete capsule (29). They can be seen at any age, originating from subendocardial or epicardial fat, or the myocardium itself. Intraluminal lipomas usually occur in the atrial septum and protrude into the cardiac cavity, mostly in the right atrium and left ventricle, and may also occur on the valve. Lipomas are usually asymptomatic, and in most cases, do not require treatment or surgical intervention; the occurrence of symptoms depends on the size and location of the tumor. The size varies from 1 to $15 \mathrm{~cm}$. CT and MRI are highly specified in displaying the lipid features of tumors. On CT, the lesion presents as a localized mass with low attenuation. On cine MR images, the mass shows hyperintense with a 

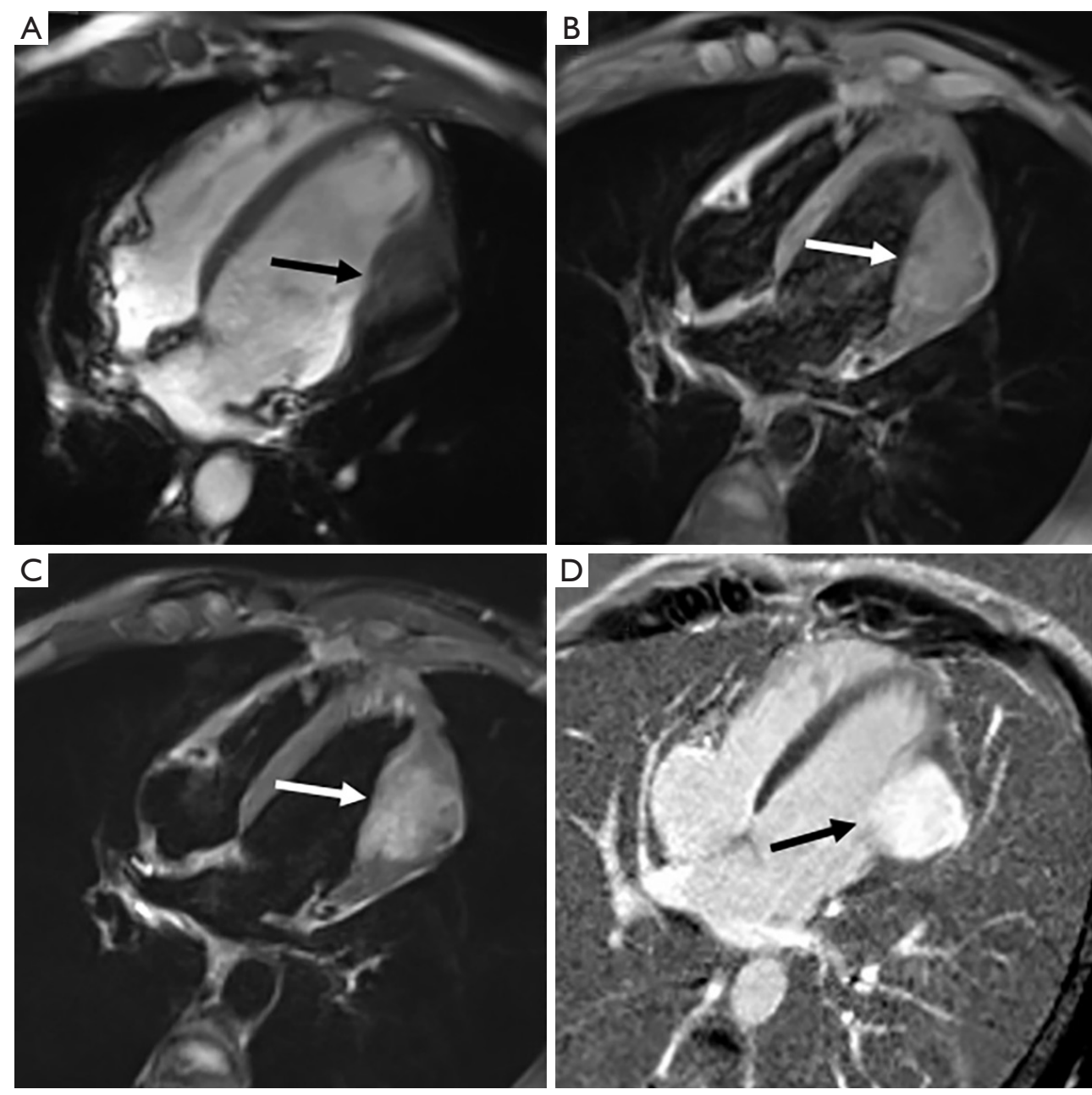

Figure 6 A 21-year-old male with chest pain for 1 month was diagnosed with left ventricular hemangioma. (A) The four-chamber plane shows the intramural mass in the left ventricular lateral wall with a homogeneous signal (black arrow). The mass is not associated with pericardial effusion, and there is no infiltrative behavior. (B) Fat-suppressed T1-weighted imaging appears isointense (white arrow). (C) Fat-suppressed T2-weighted imaging appears slightly hyperintense (white arrow). (D) Avid enhancement on LGE image (black arrow). LGE, late gadolinium enhancement.

chemical-shift dark rim. Both T1- and T2-weighted imaging present homogeneous hyperintensity (22), with signal dropout during fat suppression (30) (Figure 8). Atrial septal lipomatous hypertrophy is defined as nonneoplastic septal fat deposition with a thickness of more than $2 \mathrm{~cm}$. Different from cardiac lipomas, atrial septal lipomatous hypertrophy is usually not in the oval fossa and appears as a dumbbell shape with no obvious fibrous capsule (31); significant uptaking of F18-FDG may be related to the brown fat content of the latter.

\section{Teratoma}

Cardiac teratomas belong to germ cell tumors, about $15 \%$ of which are considered malignant. Teratomas are usually benign tumors in infancy (32). Most patients experience clinical symptoms of respiratory distress, cyanosis, and congestive heart failure during the neonatal period, which are associated with massive pericardial effusion and cardiac tamponade. It has been reported that pregnant women with teratoma have higher serum alpha-fetoprotein (AFP) levels. Teratoma is usually a pedicle tumor located in the pericardium. The tumor has a smooth and lobulated appearance. It mostly originates from the root of the ascending aorta. Teratoma consists of endoderm, mesoderm, and neuroectoderm layers, and can be cystic or solid (21). Tumors include mature or immature glial tissue, and 

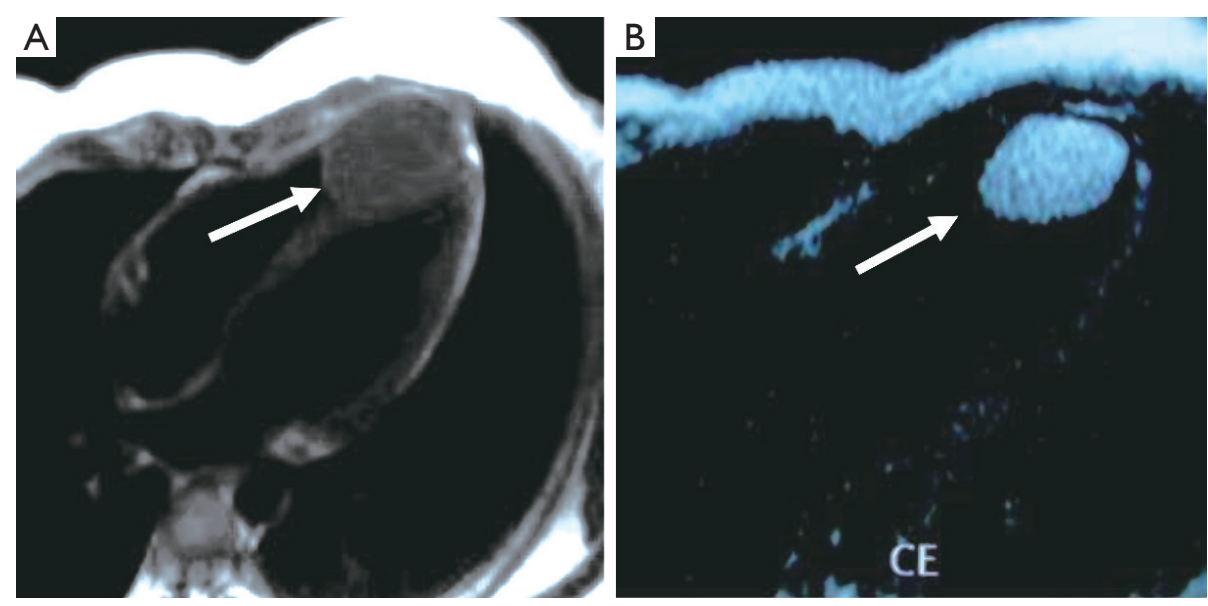

Figure 7 A non-infiltrative intramural mass at the apex of the left ventricle is seen in a 15-year-old girl and diagnosed as fibroma. (A) It manifests as a well-delimited aspect and obvious hypointensity on T2-weighted imaging (arrow). (B) Because of the hypovascular and fibrotic nature of this lesion, it is typically hyperintense on late-enhancement imaging (arrow).
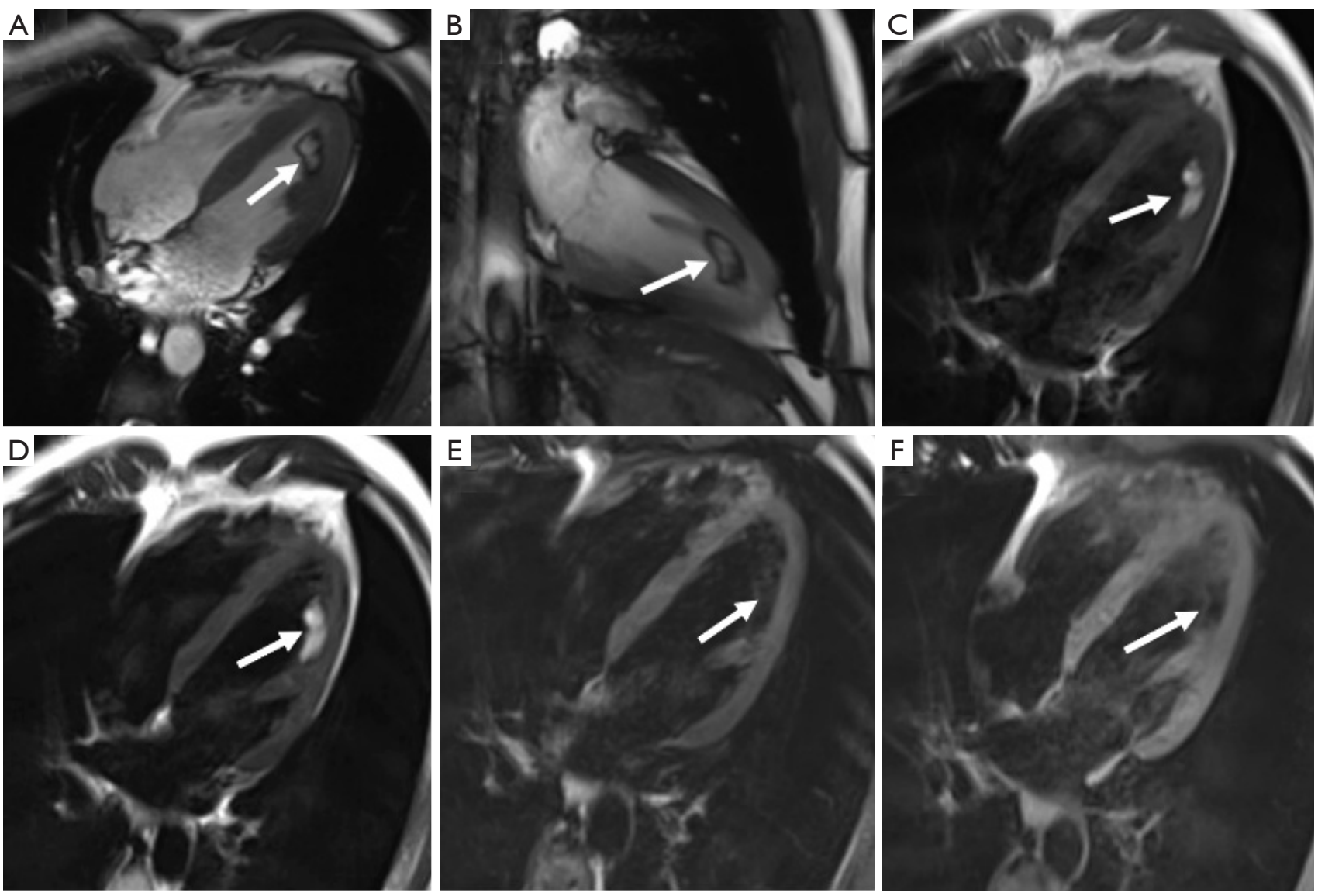

Figure 8 A 24-year-old male had intermittent precordial discomfort diagnosed with lipoma. (A,B) An irregular mass in the left ventricle on the four-chamber and short-axis planes. On cine images, the center signal of the mass is slightly higher, the boundary signal is lower, and the global signal is homogeneous (arrows). (C,D) Hyperintense appearance within the mass is observed on both T1- and T2-weighted images (arrows). (E,F) T1- and T2-weighted imaging fat suppression sequences show signal dropout (arrows). 
thyroid, pancreas, smooth muscle, skeletal muscle, bone, and cartilage lesions. Early surgical excision may improve the prognosis. Teratoma is composed of cystic components and often compresses the superior vena cava and the right atrium, resulting in decreased cardiac output and pericardial effusion. CMR can help to better determine the relationship between large masses and adjacent structures (Figure 9). Early diagnosis of cardiac teratomas is important because most can be cured by surgical excision. The differential diagnosis of these benign cardiac tumors is listed in Table 3.

\section{Imaging diagnosis of malignant cardiac tumors}

\section{Mesothelioma}

Mesothelioma is malignant and mainly originates from pericardial mesothelial cells. It is common in elderly men who have a history of asbestos exposure and pleural changes. It is usually manifested by diffuse growth, multiple, ill-defined masses within the pericardial cavity giving rise to extensive pericardial thickening, and a large amount of hemorrhagic pericardial effusion. Patients with diffuse pericardial involvement may present with symptoms and signs of constrictive pericarditis or cardiac tamponade. In patients with advanced tumors, extensive metastasis may occur. The tumor rarely invades the myocardium (33). The compression of the atrial and ventricles by the tumor can lead to cardiac deformation. CMR shows pericardial mass, which is surrounded by the visceral and parietal pericardium (Figure 10). The tumor presents as isointense on T1weighted and heterogeneous intense on $\mathrm{T} 2$-weighted imaging. Avid enhancement can be observed after contrastmedium administration. The hemosiderosis presents as low signal intensity on T2-weighted imaging. Abnormal nodular signals protrude from the pericardium suggesting tumor invasion as a malignant sign. Surgical treatment combined with radiotherapy is the main treatment, and the prognosis of all patients is extremely poor, with a survival period of about 6 months to 1 year (34).

\section{Angiosarcoma}

Angiosarcoma is the most common malignant tumor of the heart, accounting for one-third of malignant cardiac tumors and less than $10 \%$ of primary cardiac tumors (35). Angiosarcoma usually occurs in middle-aged patients, with a ratio of 2:1 between men and women, and it is rare in children. The primary features of angiosarcoma include rapid proliferation, extensive infiltration, and distant metastasis. Tumors are mostly located in the right atrium (75\%) near the atrioventricular sulcus and often extend to the pericardium (Figure 11). Angiosarcomas can rapidly invade adjacent structures, including the superior vena cava, tricuspid valve, right ventricular free wall, interventricular
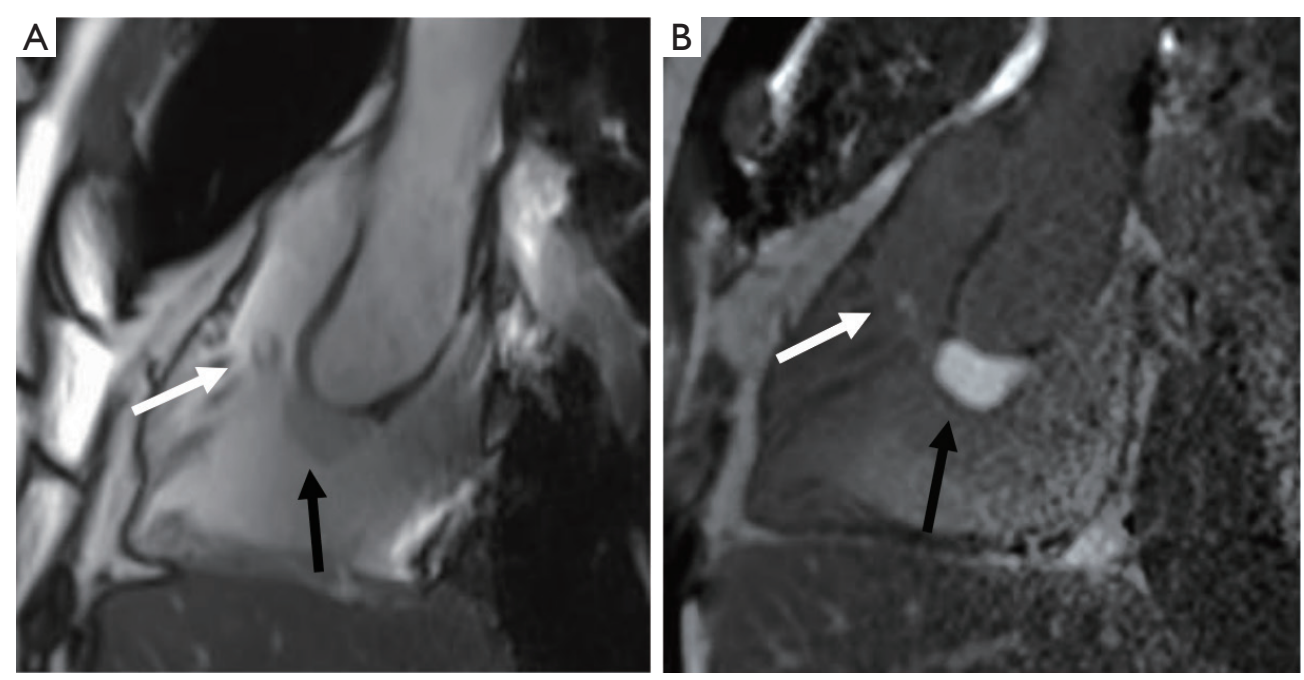

Figure 9 Teratoma in a 65-year-old male with chest pressure and hyperhidrosis after exercise. (A) CMR cine images indicate multiple masses on the right ventricular outflow tract (white arrow) and right interventricular septum (black arrow). (B) Obvious and mild enhancement is seen in the right interventricular septum (black arrow) and right ventricular outflow tract (white arrow) masses separately on the LGE image. CMR, cardiac magnetic resonance; LGE, late gadolinium enhancement. 
Table 3 Features of primary benign cardiac tumors

\begin{tabular}{|c|c|c|c|c|c|c|c|}
\hline Tumor & Percentage & $\begin{array}{l}\text { Common } \\
\text { age }\end{array}$ & Related diseases & Location of tumor & Morphologic features & Echo features & CT features \\
\hline Myxoma & $52 \%$ & $\begin{array}{l}30-60 \\
\text { years }\end{array}$ & Carney syndrome & $\begin{array}{l}\text { Fossa ovale of atrial } \\
\text { septum (left atrium } \\
80 \% \text {, right atrium } \\
20 \% \text { ) }\end{array}$ & $\begin{array}{l}\text { Gelatinous, } \\
\text { calcification, } \\
\text { hemorrhage or } \\
\text { necrosis }\end{array}$ & $\begin{array}{l}\text { Mobile tumor with } \\
\text { narrow stalk, hypo or } \\
\text { hyperechoic }\end{array}$ & $\begin{array}{l}\text { Heterogeneous, } \\
\text { low attenuation, } \\
\text { calcification } \\
\text { (frequent) }\end{array}$ \\
\hline $\begin{array}{l}\text { Papillary } \\
\text { fibroelastoma }\end{array}$ & $16 \%$ & $\begin{array}{l}60-80 \\
\text { years }\end{array}$ & No & $\begin{array}{l}\text { Cardiac valve (usually } \\
\text { left sited), away from } \\
\text { valvular free edge }\end{array}$ & $\begin{array}{l}\text { Small }(<1 \mathrm{~cm}) \text {, minimal } \\
\text { short thin stalk, } \\
\text { calcification rare }\end{array}$ & $\begin{array}{l}\text { Mobile mass, with } \\
\text { short pedicle }\end{array}$ & Usually not seen \\
\hline Rhabdomyoma & $1 \%$ & Children & $\begin{array}{l}\text { Tuberous sclerosis } \\
(50 \%)\end{array}$ & $\begin{array}{l}\text { Ventricle, inter- } \\
\text { ventricular septum }\end{array}$ & $\begin{array}{l}\text { Lobulated, usually } \\
\text { multiple intramural } \\
\text { nodules }\end{array}$ & $\begin{array}{l}\text { Hyperechoic, } \\
\text { contiguous with } \\
\text { myocardium }\end{array}$ & $\begin{array}{l}\text { Difficult to see } \\
\text { because isodensity } \\
\text { with myocardium }\end{array}$ \\
\hline Hemangioma & $6 \%$ & All ages & $\begin{array}{l}\text { Kasabach-Merritt } \\
\text { syndrome or } \\
\text { hemangioma of } \\
\text { multiple systems }\end{array}$ & $\begin{array}{l}\text { Ventricle, inter- } \\
\text { ventricular septum }\end{array}$ & $\begin{array}{l}\text { Polypoid or sessile, } \\
\text { endocardial or } \\
\text { intramyocardial } \\
\text { nodule }(2-4 \mathrm{~cm})\end{array}$ & Hyperechoic & $\begin{array}{l}\text { Heterogeneous, } \\
\text { calcification }\end{array}$ \\
\hline Fibroma & $3 \%$ & $\begin{array}{l}\text { Infants, } \\
\text { children }\end{array}$ & Gorlin syndrome & $\begin{array}{l}\text { Inter-ventricular } \\
\text { septum, left ventricle } \\
\text { wall, right ventricle }\end{array}$ & $\begin{array}{l}\text { Mean size } 5 \mathrm{~cm} \text {, } \\
\text { calcification common, } \\
\text { no hemorrhage }\end{array}$ & $\begin{array}{l}\text { Intramural, } \\
\text { homogeneous echo }\end{array}$ & $\begin{array}{l}\text { Low attenuation, } \\
\text { calcification }\end{array}$ \\
\hline Lipoma & $16 \%$ & Any age & $\begin{array}{l}\text { Partial cases with } \\
\text { tuberous sclerosis }\end{array}$ & $\begin{array}{l}\text { Epicardial }(70 \%) \text {, } \\
\text { ventricle, inter-atrial } \\
\text { septum }\end{array}$ & Smooth, broad-based & $\begin{array}{l}\text { Hypoechoic in } \\
\text { pericardial space or } \\
\text { intracavitary }\end{array}$ & $\begin{array}{l}\text { Homogeneous, fat } \\
\text { attenuation }\end{array}$ \\
\hline Teratoma & $1 \%$ & $\begin{array}{l}\text { Infants, } \\
\text { children }\end{array}$ & $\begin{array}{l}\text { Pericardial } \\
\text { effusion, cardiac } \\
\text { tamponade, fetal } \\
\text { abortion }\end{array}$ & $\begin{array}{l}\text { Intrapericardial, right } \\
\text { heart, inter-atrial } \\
\text { or inter-ventricular } \\
\text { septum }\end{array}$ & $\begin{array}{l}\text { Multilocular cystic and } \\
\text { solid mass }\end{array}$ & Heterogeneous echo & $\begin{array}{l}\text { Heterogeneous } \\
\text { attenuation }\end{array}$ \\
\hline
\end{tabular}

septum, and even the right coronary artery, with clinical symptoms of chest pain or arrhythmias. The lung is the most common metastatic site followed by the liver and brain (36). Morphologically, angiosarcoma is a hemorrhagic mass with ill-defined margins and multiple necroses, calcification, and lobulation. The pericardial morphology is characterized by invasive pericardial masses, pericardial thickening, and hemorrhagic pericardial effusion, with right heart failure and cardiac tamponade as the most common manifestations. The heterogeneous hyperintense appearance on T1- and T2-weighted imaging is consistent with the necrosis and hemorrhage within the tumor, which is like a "cauliflower." The tumor is characterized by obvious enhancement with a "sunray" appearance (37). The large intralesional vessels are often shown as empty blood flow signals on CMR.

\section{Leiomyosarcoma}

Cardiac leiomyosarcoma accounts for $1 \%$ of all cardiac tumors and $8-9 \%$ of all cardiac sarcomas. The age of onset is usually about 40 years old. Primary cardiac leiomyosarcoma mainly occurs in the left atrium (60\%) (Figure 12), and other locations including the right ventricle $(20 \%)$, the right atrium (15\%), and the left ventricle $(5 \%)$. The tumor shows invasive growth patterns, involving heart valves or occupying two or more cardiac cavities (22\%). Because the left atrium and pulmonary vein are vulnerable to invasion, dyspnea and heart failure occur clinically due to mitral valve obstruction (38). Leiomyosarcoma often has multiple $(30 \%)$, sessile, lobulated, or nodular masses, with strong nuclear heteromorphism and high mitotic activity. Histologic examination shows mucoid stroma, and tumor cells can be fusiform, epithelial, or pleomorphic. CMR shows hypo- or isointense on T1-weighted imaging and often hyperintense on T2-weighted imaging. There is an obvious heterogeneous enhancement on LGE. The low perfusion area of the tumor is associated with internal necrosis. Surgical resection is an important treatment for cardiac leiomyosarcoma, which can be treated with adjuvant chemotherapy. However, half of the patients 

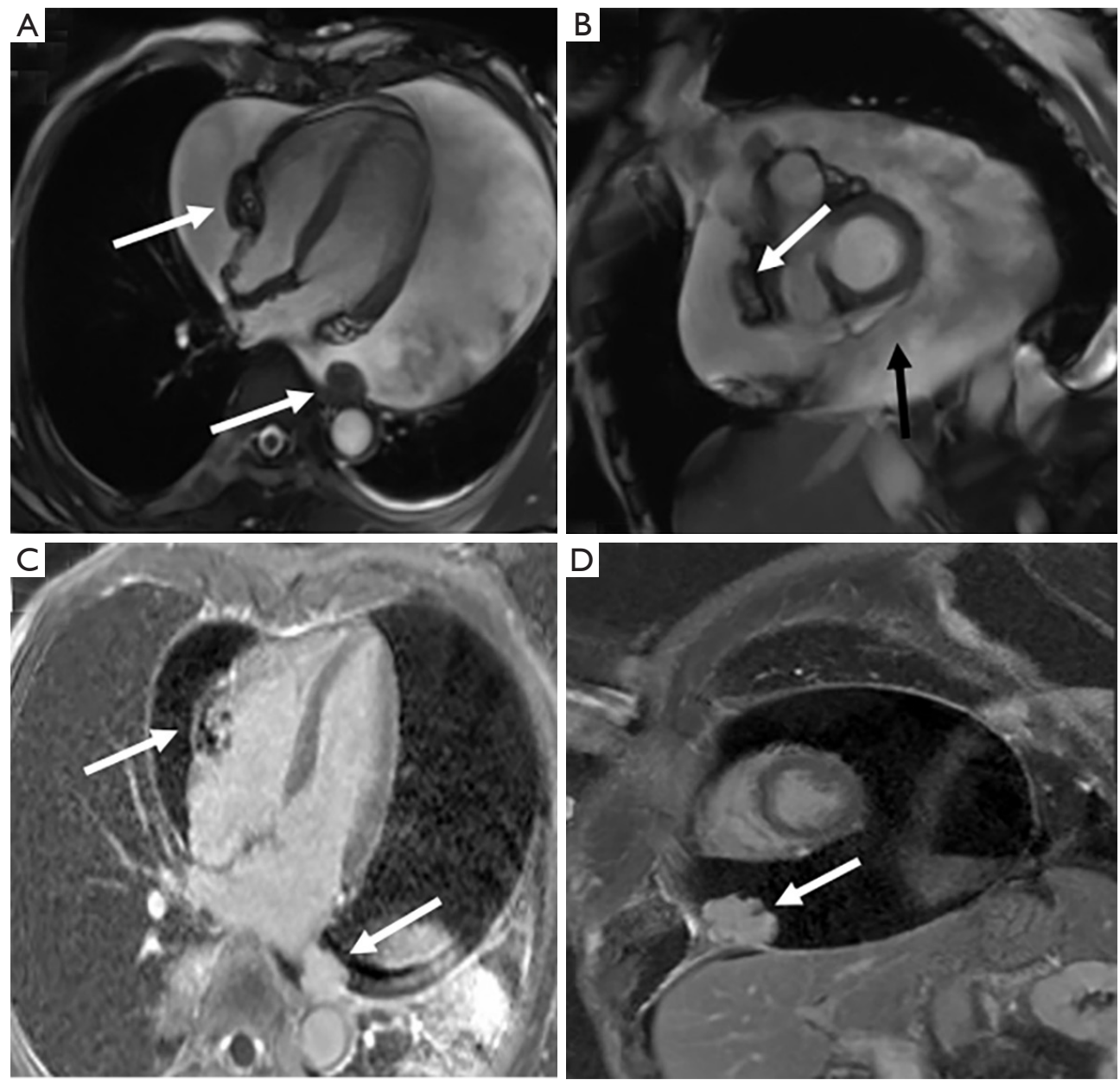

Figure 10 Pericardial mesothelioma in a 71-year-old male with shortness of breath. (A,B) Multiple nodular masses in the pericardial cavity are observed on CMR cine images (white arrows). The irregular masses invade the visceral and parietal pericardium, resulting in pericardial thickening and massive pericardial effusion (black arrow). (C,D) Noteworthy heterogeneous enhancement visible in the masses (arrows). CMR, cardiac magnetic resonance.

have postoperative recurrence and metastasis. The median survival time without recurrence is about 14 months (39).

\section{Synovial sarcoma}

Primary synovial sarcomas of the heart are common in men, with a male-to-female ratio of about $3: 1$. The average age of the patients is 37.1 years old (40). Dyspnea is the most common symptom. The most common site is the pericardium (40\%), followed by the right atrium (24\%) and the left atrium (8\%). Most of the tumors are polypoid and lobulated solid masses with a smooth surface and welldefined border. It is characterized by a large mass with a broad base and does not spread extensively or infiltrate into the surrounding structure. Most tumors have pedicels or stalks. Pathologically, it can be divided into monophasic, biphasic, and poorly differentiated types. Cytogenetics indicates that the SYT-SSX fusion gene is the gold standard for the diagnosis of synovial sarcoma. Pericardiocentesis is usually hemorrhagic pericardial effusion. CMR detects heterogeneous soft tissue mass occasionally with poly cysts or septa (Figure 13). Heterogeneous enhancement can be observed on LGE imaging (41). The treatment is surgery, supplemented by radiotherapy, chemotherapy, or targeted therapy. Heart transplantation is recommended for patients with diffuse heart invasion. Synovial sarcoma is prone to metastasis and recurrence. Early diagnosis and complete resection can improve prognosis. 

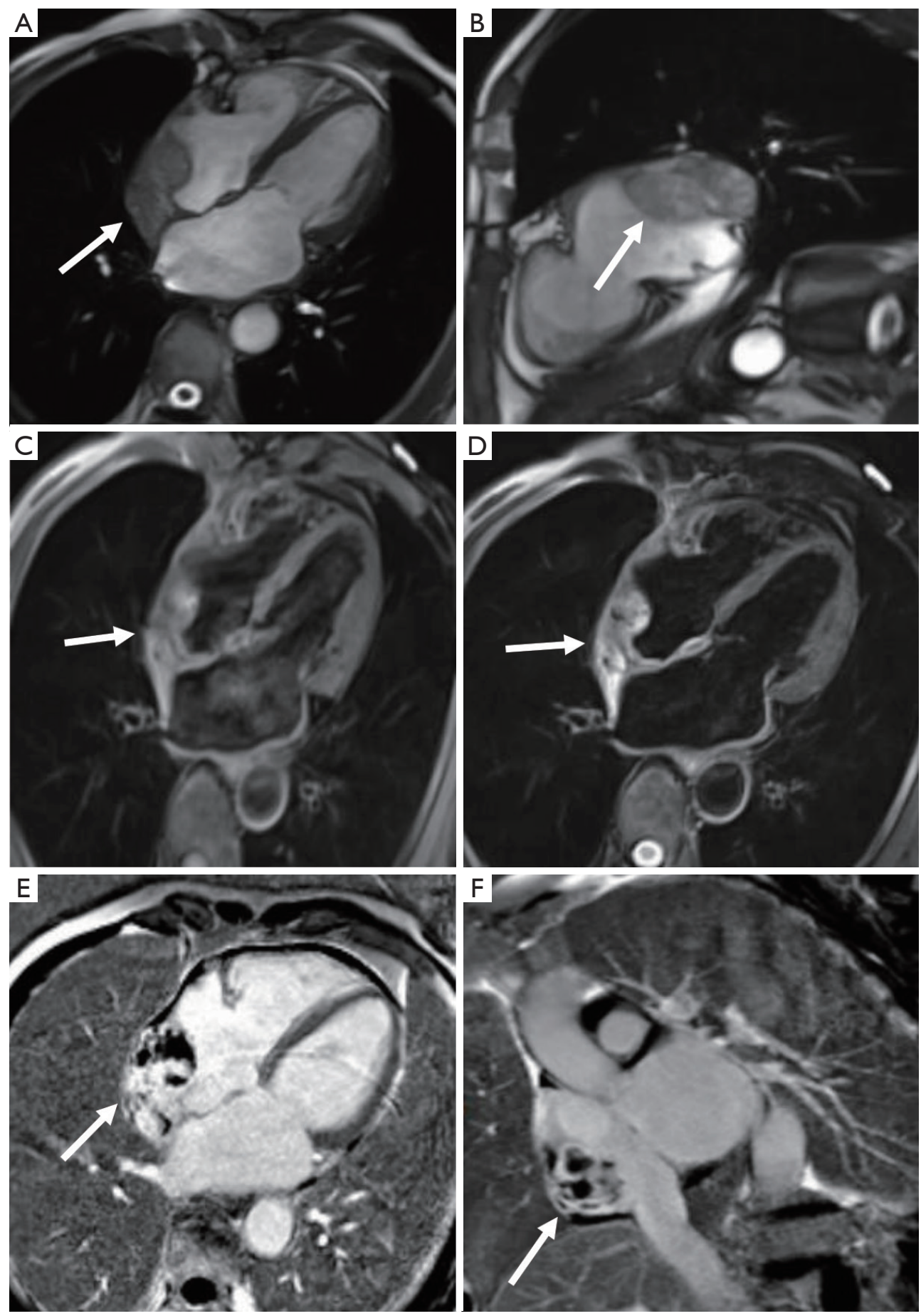

Figure 11 Angiosarcoma in a 74-year-old male with dyspnea on exertion. (A,B) CMR cine images demonstrate an irregular mass on the roof of the right atrium with a well- defined aspect and protrusion outward from the pericardium (arrows). (C,D) The fat saturation sequences of T1- and T2-weighted imaging reveal intense heterogeneous signals (arrows). (E,F) There is marked heterogeneous enhancement within the mass on LGE images (arrows). CMR, cardiac magnetic resonance; LGE, late gadolinium enhancement. 

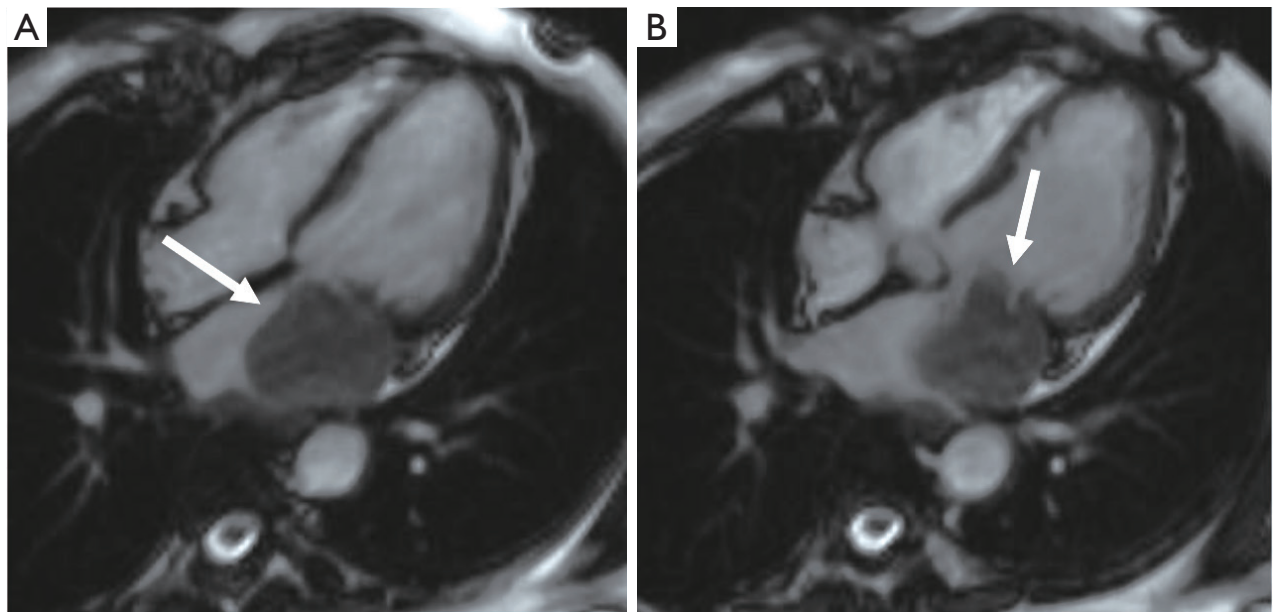

Figure 12 Leiomyosarcoma in a 55-year-old woman with chest tightness for half a year after exercise and pain in the left chest and back. (A,B) The cardiac cine images depict an irregular mass in the left atrial, the boundary between the mass and the lateral wall of the left atrium is illdefined, and the mitral valve is involved forward (arrows).
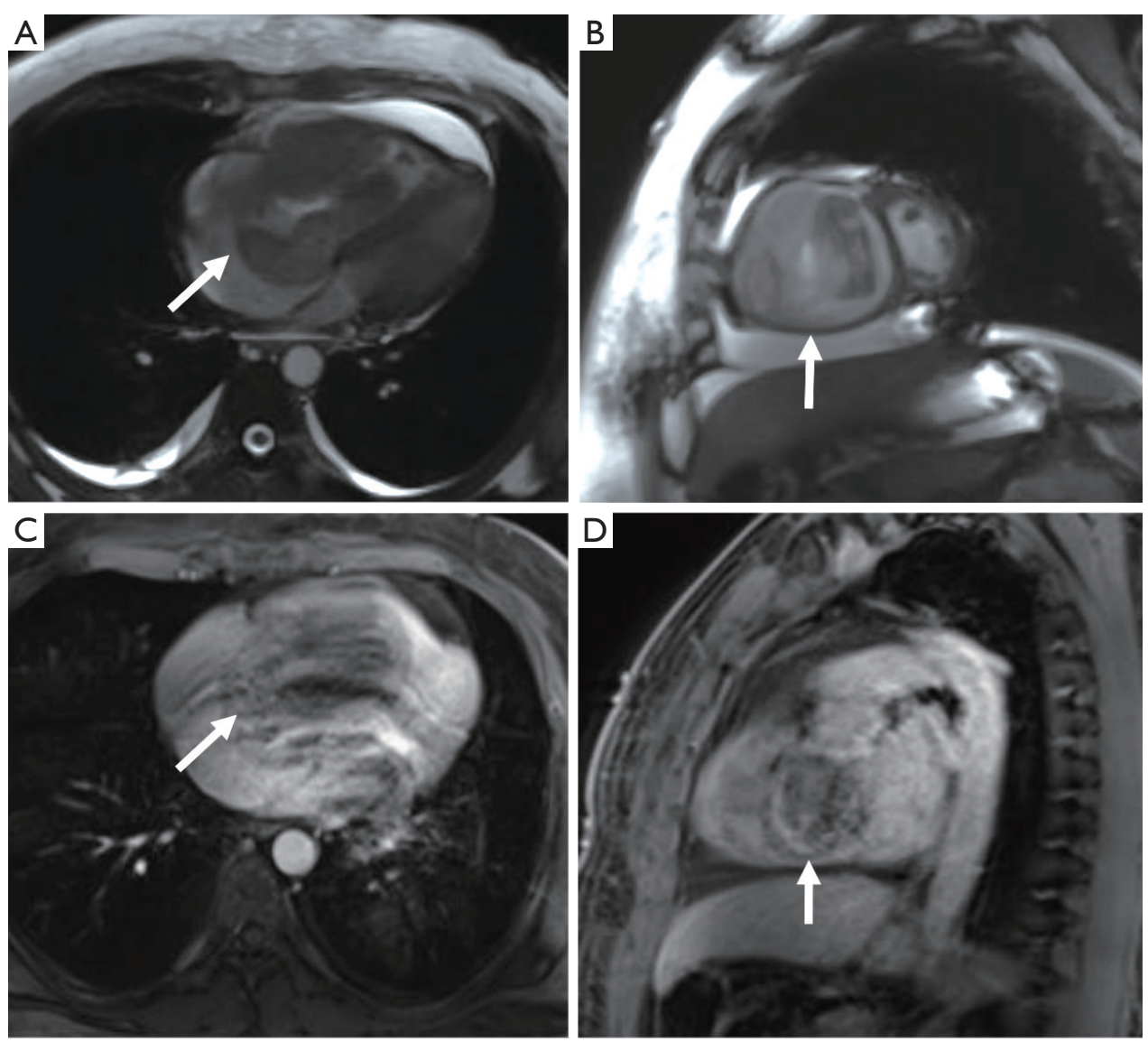

Figure 13 Synovial sarcoma in a 32-year-old male presenting with symptoms of abdominal distension for more than one month. (A,B) Cine images show the right atrioventricular mass with irregular shape (arrows), swinging back and forth between the right atrium and ventricle. (C,D) Heterogeneous enhancement is observed in the mass after contrast agent administration (arrows). 

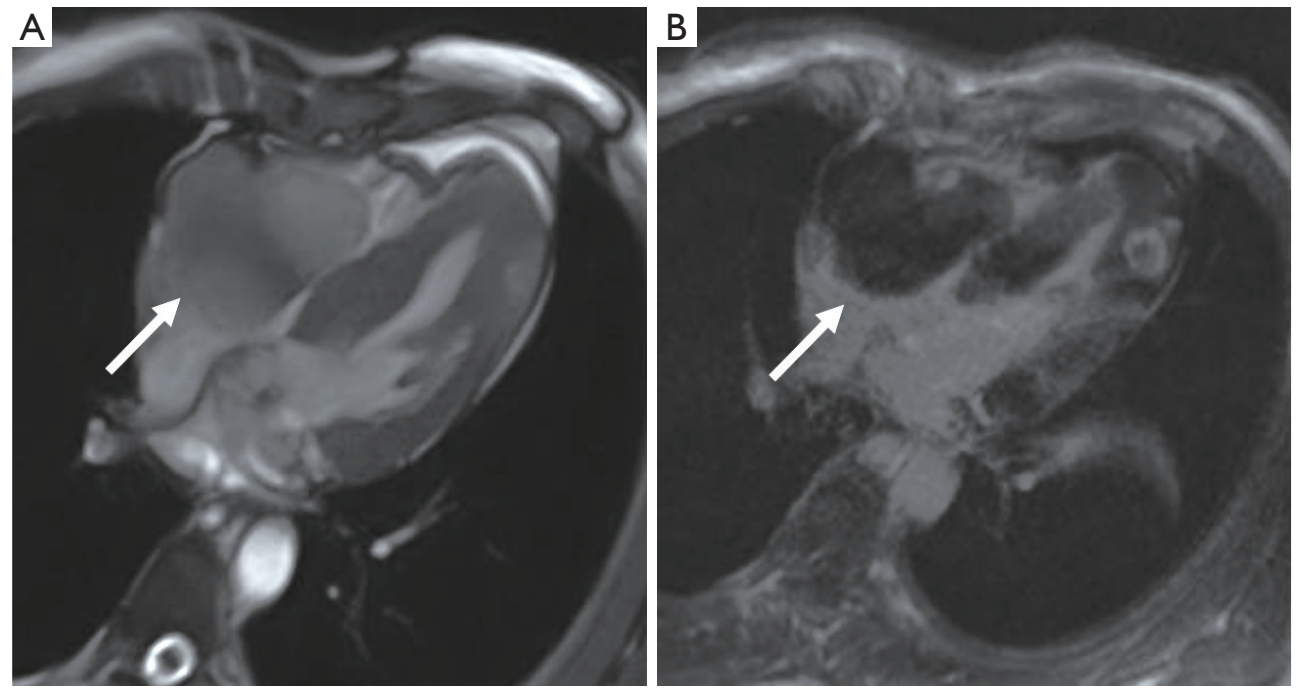

Figure 14 Lymphoma in a 40-year-old male. (A) An irregular mass originating from the right atrioventricular sulcus in a cine image (arrow). The isointense mass has an invasive aspect and is associated with pericardial effusion. (B) Notably, the mass is shown with mild contrast enhancement on LGE imaging (arrow). LGE, late gadolinium enhancement.

\section{Lymphoma}

Primary cardiac lymphoma accounts for $1.3 \%$ of primary cardiac tumors and is defined as extranodal non-Hodgkin's lymphoma invading the right atrium or pericardium. Most patients have diffuse large B-cell lymphomas and are on average 60 years old. In immunocompromised patients, cardiac lymphoma is associated with EB-virus infection, and it is also present in patients with AIDS (42). Typical clinical manifestations are dyspnea, chest pain, and arrhythmia. About $75 \%$ of primary cardiac lymphoma involves more than one chamber leading to superior vena cava obstruction, pericardial tamponade, or sudden death (43). Lymphoma mostly grows along the epicardial surface and surrounds the coronary arteries and aortic roots, which often leads to pericardial thickening and massive pericardial effusion. Histological and immunohistochemical examination of the affected tissue may confirm the diagnosis. Tumors are usually hypo- or isointense on T1-weighted imaging and slightly hyperintense on $\mathrm{T} 2$-weighted imaging, with mild enhancement after contrast agent administration (Figure 14). Necrosis and hemorrhage are rare in lymphoma. Cardiac lymphoma is highly metabolic and presents as clear F18-FDG uptake, so PET imaging is a valuable method for the initial diagnosis of cardiac lymphoma and has been proven to improve the detection rate of the lesion (44). Chemotherapy and radiotherapy are the main treatments. Also, studies have shown that F18-FDG imaging can be used to evaluate the response of cardiac lymphoma to treatment. The median survival of lymphoma is about 12 months.

\section{Rhabdomyosarcoma}

Rhabdomyosarcoma is the most common primary malignant tumor of the heart in infants and children (45), with $75 \%$ of cases occurring in children under 1 year of age. Rhabdomyosarcoma may originate anywhere in the heart, and $60 \%$ of cases are multicenter located. The incidence of cardiac rhabdomyosarcoma in males is slightly higher than that in females, with a ratio of 1 to 1.4. Primary cardiac rhabdomyosarcoma often involves the myocardium, with no chamber predilection. The tumor is large and aggressive, with a maximum diameter of more than $10 \mathrm{~cm}$ (46). Pathologically, rhabdomyosarcoma is divided into three subtypes: embryonic type (in children), alveolar type, and pleomorphism (in adults). The clinical manifestations are arrhythmia and heart failure. It is reported that patients with cardiac rhabdomyosarcoma can show eosinophilia. Compared with angiosarcoma, rhabdomyosarcoma is more likely to invade the pericardium or valves and manifests in a nodular form rather than as patchy diffusion. CT shows an irregular, smooth, low-attenuation mass. CMR often shows isointense on T1- and T2-weighted imaging, with the central necrosis of the tumor being a distinctive feature (47). Rhabdomyosarcoma is usually characterized 


\begin{tabular}{|c|c|c|c|c|c|c|}
\hline Tumor & Percentage & Common age & Location of tumor & Morphologic features & Echo features & CT features \\
\hline Mesothelioma & $4 \%$ & Elderly men & $\begin{array}{l}\text { Pericardial } \\
\text { (asbestos } \\
\text { exposure or pleural } \\
\text { changes) }\end{array}$ & $\begin{array}{l}\text { Diffuse growth, multiple, } \\
\text { calcification, ill-defined } \\
\text { masses }\end{array}$ & $\begin{array}{l}\text { Echo of } \\
\text { intrapericardial nodules, } \\
\text { pericardial effusion }\end{array}$ & $\begin{array}{l}\text { Extensive } \\
\text { pericardial } \\
\text { thickening, } \\
\text { pericardial effusion }\end{array}$ \\
\hline Angiosarcoma & $30 \%$ & $\begin{array}{l}30-50 \text { years, } M: \\
F=3: 1\end{array}$ & Right atrium (75\%) & $\begin{array}{l}\text { Large infiltrating broad- } \\
\text { base mass, hemorrhage } \\
\text { and necrosis }\end{array}$ & $\begin{array}{l}\text { Mass protruding } \\
\text { into right atrium, } \\
\text { pericardial effusion }\end{array}$ & $\begin{array}{l}\text { Heterogeneous } \\
\text { attenuation }\end{array}$ \\
\hline Leiomyosarcoma & $5 \%$ & 40 years & $\begin{array}{l}\text { Left atrium }(60 \%) \\
\text { posterior wall }\end{array}$ & $\begin{array}{l}\text { Multiple }(30 \%) \text {, sessile, } \\
\text { lobulated or nodular }\end{array}$ & $\begin{array}{l}\text { Mass in posterior wall of } \\
\text { left atrium, involvement } \\
\text { of pulmonary vein and } \\
\text { mitral valve }\end{array}$ & Low attenuation \\
\hline Synovial sarcoma & $10-15 \%$ & $\begin{array}{l}37.1 \text { years, } M: F \\
=3: 1\end{array}$ & $\begin{array}{l}\text { Pericardium, right } \\
\text { atrium }\end{array}$ & $\begin{array}{l}\text { Smooth, polypoid and } \\
\text { lobulated solid masses }\end{array}$ & Intracavitary lesion & Low attenuation \\
\hline Lymphoma & $5 \%$ & $\begin{array}{l}60 \text { years, } M: F \\
=3: 1\end{array}$ & Right atrium & $\begin{array}{l}\text { Homogeneous } \\
\text { nodule extends into } \\
\text { pericardium }\end{array}$ & $\begin{array}{l}\text { Infiltrating mass involves } \\
\text { more than one chamber } \\
(75 \%)\end{array}$ & $\begin{array}{l}\text { Pericardial } \\
\text { thickening, } \\
\text { pericardial effusion }\end{array}$ \\
\hline Rhabdomyosarcoma & $10 \%$ & Infants, children & Any chamber & $\begin{array}{l}\text { Large and aggressive, } \\
\text { smooth or irregular, } \\
\text { central necrosis }\end{array}$ & $\begin{array}{l}\text { Multiple nodular } \\
\text { masses, valves and } \\
\text { pericardium invasion }\end{array}$ & Low attenuation \\
\hline
\end{tabular}

by heterogeneous enhancement. Rhabdomyosarcoma of the heart needs active treatment, often with a survival period of less than 1 year, and tends to produce local or distant metastasis. Surgical resection is a common treatment, which can be combined with chemotherapy or radiotherapy. Table 4 summarizes the common characteristics and distinguishing points of common cardiac malignant tumors.

\section{New techniques for delineating cardiac tumors}

CMR is highly accurate in the identification of benign and malignant cardiac masses (including tumor and nontumor masses), with tumor size, local infiltration, and enhanced initial perfusion being the most reliable indicators to evaluate the degree of tumor malignancy. 3D-MRA is a new sequence that diagnoses cardiac tumors and can show vascular involvement. 3D reconstruction is a valuable auxiliary method for preoperative evaluation of cardiac masses, which can better describe the margin of the mass and its relationship with the surrounding structure (48). 3D printing is an emerging technology that makes the edges of cardiac tumors easier to visualize. The $3 \mathrm{D}$ printed models have been incorporated into the management of different types of tumors such as hepatocellular carcinoma and renal cell carcinoma with promising outcomes reported (49-51).
Thus, it may have added value in the visualization and presurgical planning of cardiac tumors.

\section{Conclusions}

CMR is a comprehensive imaging method that can evaluate the characteristics of cardiac tumors. CMR can assess (I) the location, size, borders, and signal characteristics of a cardiac mass; (II) complications such as valve stenosis or insufficiency, pericardial effusion; (III) the overall structure and function of the normal heart along with myocardial perfusion; (IV) the contrast enhancement scan showing the relationship between the tumor and blood vessels, the vascularity of the tumor, and the degree of enhancement; (V) relationship between tumor and pericardium, lung, or mediastinum. Furthermore, CMR imaging has a significant diagnostic value for the signal characteristics of tissue components within tumors, including calcification, fat, fibrosis, hemorrhage, and cystic changes. The shape, anatomical location, histological features, and the impact on cardiac function of a tumor can be implemented in a single examination-so-called "one-stop assessment". Table 5 shows the CMR signal characteristics of common benign and malignant cardiac tumors.

The fundamental role of CMR in the treatment of 
Table 5 CMR characteristics of primary cardiac tumors

\begin{tabular}{|c|c|c|c|c|}
\hline Cardiac masses & Cine-MR imaging & T1-weighted & T2-weighted & LGE \\
\hline Rhabdomyoma & $\begin{array}{l}\text { Slightly hyperintense, } \\
\text { intramural mass }\end{array}$ & Iso- or hyperintense & Slightly hyperintense & Hypointense or isointense \\
\hline Hemangioma & Hyperintense & Isointense & Hyperintense & $\begin{array}{l}\text { Heterogeneous prolonged } \\
\text { enhancement }\end{array}$ \\
\hline Fibroma & Hypo- or isointense & Iso- or hyperintense & Hypointense & $\begin{array}{l}\text { Homogeneous late } \\
\text { enhancement }\end{array}$ \\
\hline Mesothelioma & Hypointense nodule & Isointense & Heterogeneous intense & $\begin{array}{l}\text { Heterogeneous } \\
\text { enhancement }\end{array}$ \\
\hline Angiosarcoma & Isointense, heterogeneous & $\begin{array}{l}\text { Heterogeneous hyperintense } \\
\text { "cauliflower" }\end{array}$ & $\begin{array}{l}\text { Heterogeneous } \\
\text { hyperintense "cauliflower" }\end{array}$ & $\begin{array}{l}\text { Avid enhancement with } \\
\text { "Sunray" aspect }\end{array}$ \\
\hline Leiomyosarcoma & Hypo- or isointense & Isointense & hyperintense & Nonspecific \\
\hline Synovial sarcoma & Hypo- or isointense & Isointense & Slightly hyperintense & $\begin{array}{l}\text { Heterogeneous } \\
\text { enhancement }\end{array}$ \\
\hline Lymphoma & Isointense & Hypo- or isointense & Slightly hyperintense & $\begin{array}{l}\text { Heterogeneous } \\
\text { enhancement }\end{array}$ \\
\hline
\end{tabular}

CMR, cardiac magnetic resonance; T1WI, T1-weighted imaging; T2WI, T2-weighted imaging; LGE, late gadolinium enhancement.

cardiac masses depends on accurate localization and qualitative diagnosis. A benign primary heart tumor can usually be removed surgically. Primary malignant tumor without surgical resection except lymphoma has a poor prognosis. In treatment planning, malignant sarcomas are usually classified according to anatomical location rather than histology. CMR imaging provides a favorable anatomic assessment of cardiac tumors and relationship with extracardiac structures, which is of immense value for preoperative and prognostic evaluation. However, the biological characteristics of different tumors may overlap, so treatment decisions are often based not on CMR imaging alone, but a combination with histopathology and laboratory testing. In summary, CMR imaging is currently considered as the preferred method for the evaluation of cardiac tumors. It is believed that with the continuous development of CMR technology, the accuracy of the diagnosis of cardiac tumors will be further improved, which will facilitate in planning the most appropriate therapeutic strategy and monitoring tumor recurrence.

\section{Acknowledgments}

Funding: This work was supported by the National Natural Science Foundation of China (81401375).

\section{Footnote}

Conflicts of Interest: The authors have no conflicts of interest to declare. 


\section{References}

1. Wang JG. Primary Cardiac Tumors. Right Heart Pathol 2018;489-514.

2. Reynen K. Frequency of primary tumors of the heart. Am J Cardiol 1996;77:107.

3. Elbardissi AW, Dearani JA, Daly RC, Mullany CJ, Orszulak TA, Puga FJ, Schaff HV. Survival after resection of primary cardiac tumors:a 48-year experience. Circulation 2008;118:S7-15.

4. Motwani M, Kidambi A, Herzog BA, Uddin A, Greenwood JP, Plein S. MR imaging of Cardiac tumors and masses: A Review of Methods and Clinical Applications. Radiology 2013;268:26-43.

5. Tumma R, Dong W, Wang J, Litt H, Han Y. Evaluation of cardiac masses by CMR — strengths and pitfalls: a tertiary center experience. Int J Cardiovasc Imaging 2016;32:913-20.

6. Mousavi N, Cheezum MK, Aghayev A, Padera R, Vita T, Steigner M, Hulten E, Bittencourt MS, Dorbala S, Di Carli MF, Kwong RY, Dunne R, Blankstein R. Assessment of Cardiac Masses by Cardiac Magnetic Resonance Imaging: Histological Correlation and Clinical Outcomes. J Am Heart Assoc 2019;8:e007829.

7. Pazos-López P, Pozo E, Siqueira ME, García-Lunar I, Cham M, Jacobi A, Macaluso F, Fuster V, Narula J, Sanz J. Value of CMR for the Differential Diagnosis of Cardiac Masses. JACC Cardiovasc Imaging 2014;7:896-905.

8. Carrascosa PM, Rodríguez-Granillo GA, Deviggiano A, Arenaza DP, De Zan MC. Cardiac Masses and Tumors. Clinical Atlas of Cardiac and Aortic CT and MRI 2019:287-307.

9. Han F, Rapacchi S, Hu P. Prospective cardiac motion selfgating. Quant Imaging Med Surg 2017;7:215-26.

10. Weinsaft JW, Kim HW, Shah DJ, Klem I, Crowley AL, Brosnan R, James OG, Patel MR, Heitner J, Parker M, Velazquez EJ, Steenbergen C, Judd RM, Kim RJ. Detection of left ventricular thrombus by delayedenhancement cardiovascular magnetic resonance prevalence and markers in patients with systolic dysfunction. J Am Coll Cardiol 2008;52:148-57.

11. Corti R, Osende JI, Fayad ZA, Fallon JT, Fuster V, Mizsei G, Dickstein E, Drayer B, Badimon JJ. In vivo noninvasive detection and age definition of arterial thrombus by MRI. J Am Coll Cardiol 2002;39:1366-73.

12. Sparrow PJ, Kurian JB, Jones TR, Sivananthan MU. MR imaging of cardiac tumors. Radiographics 2005;25:1255-76.

13. Restrepo CS, Largoza A, Lemos DF, Diethelm L, Koshy
P, Castillo P, Gomez R, Moncada R, Pandit M. CT and MR imaging findings of benign cardiac tumors. Curr Prob Diagn Radiol 2005;34:12-21.

14. Salanitri J, Lisle D, Rigsby C, Slaughter R, Edelman R. Benign cardiac tumours: Cardiac CT and MRI imaging appearances. J Med Imaging Radiat Oncol 2008;52:550-8.

15. Jain S, Maleszewski JJ, Stephenson CR, Klarich KW. Current diagnosis and management of cardiac myxomas. Expert Rev Cardiovasc Ther 2015;13:369-75.

16. Grebenc ML, Rosado-de-Christenson ML, Green CE, Burke AP, Galvin JR. Cardiac myxoma: imaging features in 83 patients. Radiographics 2002;22:673-89.

17. Shi L, Wu L, Fang H, Han B, Yang J, Ma X, Liu F, Zhang Y, Xiao T, Huang M, Huang M. Identification and clinical course of 166 pediatric cardiac tumors. Eur J Pediatr 2017;176:253-60.

18. Poterucha TJ, Kochav J, O'Connor DS, Rosner GF. Cardiac Tumors: Clinical Presentation, Diagnosis, and Management. Curr Treat Options Oncol 2019;20:66.

19. Bruce CJ. Cardiac tumours: diagnosis and management. Heart 2011;97:151-60.

20. Tiberio D, Franz DN, Phillips JR. Regression of a cardiac rhabdomyoma in a patient receiving everolimus. Pediatrics 2011;127:e1335-7.

21. O'Donnell DH, Abbara S, Chaithiraphan V, Yared K, Killeen RP, Cury RC, Dodd JD. Cardiac tumors: optimal cardiac MR sequences and spectrum of imaging appearances. AJR Am J Roentgenol 2009;193:377-87.

22. Beroukhim RS, Prakash A, Buechel ER, Cava JR, Dorfman AL, Festa P, Hlavacek AM, Johnson TR, Keller MS, Krishnamurthy R, Misra N, Moniotte S, Parks WJ, Powell AJ, Soriano BD, Srichai MB, Yoo SJ, Zhou J, Geva T. Characterization of cardiac tumors in children by cardiovascular magnetic resonance imaging: a multicenter experience. J Am Coll Cardiol 2011;58:1044-54.

23. Koçak H, Ozyazicioğlu A, Gündoğdu C, Sevimli S. Cardiac hemangioma complicated with cerebral and coronary embolization. Heart Vessels 2005;20:296-7.

24. Eftychiou C, Antoniades L. Cardiac hemangioma in the left ventricle and brief review of the literature. J Cardiovasc Med (Hagerstown) 2009;10:565-7.

25. Oshima H, Hara M, Kono T, Shibamoto Y, Mishima A, Akita S. Cardiac hemangioma of the left atrial appendage: CT and MR findings. J Thorac Imaging 2003;18:204-6.

26. Tao TY, Yahyavi-Firouz-Abadi N, Singh GK, Bhalla S. Pediatric Cardiac Tumors: Clinical and Imaging Features. RadioGraphics 2014;34:1031-46.

27. Yan AT, Coffey DM, Li Y, Chan WS, Shayne AJ, Luu 
TM, Skorstad RB, Khin MM, Brown KA, Lipton MJ, Kwong RY. Images in cardiovascular medicine. Myocardial fibroma in gorlin syndrome by cardiac magnetic resonance imaging. Circulation 2006;114:e376-79.

28. Kiaffas MG, Powell AJ, Geva T. Magnetic resonance imaging evaluation of cardiac tumor characteristics in infants and children. Am J Cardiol 2002;89:1229-33.

29. Grizzard JD, Ang GB. Magnetic resonance imaging of pericardial disease and cardiac masses. Cardiol Clin 2007;25:111-40.

30. Grebenc ML, Rosado de Christenson ML, Burke AP, Green CE, Galvin JR. Primary cardiac and pericardial neoplasms: radiologic-pathologic correlation.

Radiographics 2000;20:1073-103.

31. Yinon Y, Chitayat D, Blaser S, Seed M, Amsalem H, Yoo SJ, Jaeggi ET. Fetal cardiac tumors: a single-center experience of 40 cases. Prenat Diagn 2010;30:941-9.

32. Wang ZJ, Reddy GP, Gotway MB, Yeh BM, Hetts SW, Higgins CB. CT and MR imaging of pericardial disease. RadioGraphics 2003;23:S167-80.

33. Kaul TK, Fields BL, Kahn DR. Primary malignant pericardial mesothelioma: a case report and review. J Cardiovasc Surg (Torino) 1994;35:261-7.

34. Cao S, Jin S, Cao J, Shen J, Zhang H, Meng Q, Pan B, Yu Y. Malignant pericardial mesothelioma: A systematic review of current practice. Herz 2018;43:61-8.

35. Butany J, Nair V, Naseemuddin A, Nair GM, Catton C, Yau T. Cardiac tumours: diagnosis and management. Lancet Oncol 2005;6:219-28.

36. Kim CH, Dancer JY, Coffey D, Zhai QJ, Reardon M, Ayala AG, Ro JY. Clinicopathologic study of 24 patients with primary cardiac sarcomas: a 10-year single institution experience. Hum Pathol 2008;39:933-8.

37. Akkaya Z, Gursoy A, Erden A. The disastrous "sun ray" sign in cardiac magnetic resonance: an indicator of angiosarcoma. Cardiol Young 2014;24:929-31.

38. Clarke NR, Mohiaddin RH, Westaby S, Banning AP. Multifocal cardiac leiomyosarcoma. Diagnosis and surveillance by transoesophageal echocardiography and contrast enhanced cardiovascular magnetic resonance. Postgrad Med J 2002;78:492-3.

39. Wang JG, Cui L, Jiang T, Li YJ, Wei ZM. Primary cardiac leiomyosarcoma: an analysis of clinical characteristics and outcome patterns. Asian Cardiovasc Thorac Ann 2015;23:623-30.

40. Wang JG, Li NN. Primary cardiac synovial sarcoma. Ann Thorac Surg 2013;95:2202-9.

41. Wolf M, Van den Brande J, Rodrigus I, Paelinck BP. Giant primary right ventricular synovial sarcoma. Eur Heart J 2014;35:2509.

42. Agrawal K, Mittal BR, Manohar K, Kashyap R, Bhattacharya A, Varma S. FDG PET/CT in detection of metastatic involvement of heart and treatment monitoring in non-Hodgkin's lymphoma. World J Nucl Med 2012;11:33-4.

43. Engelen MA, Juergens KU, Breithardt G, Eckardt L. Interatrial conduction delay and atrioventricular block due to primary cardiac lymphoma. J Cardiovasc Electrophysiol 2005;16:926.

44. Castelli JB, Alexandre L, Futuro G, Scanavacca M, Soares Júnior J. Primary cardiac lymphoma detected by F18- FDG PET scan: a case report. J Nucl Cardiol 2011;18:974-7.

45. Wu PWP, Chen SJ, Lin WC, Chang CB, Chuang WY, Hsu MY, Liu YC, Chu JJ, Lin PJ, Wen MS, Hung KC, Wan YL. Imaging of Cardiac and Pericardial Masses. Cardiovasc Imaging Asia 2017;1:23-37.

46. Ashraf T, Day TG, Marek J, Hughes M, Giardini A. A Triad: Cardiac Rhabdomyosarcoma, Stroke and Tamponade. Pediatr Cardiol 2013;34:771-3.

47. Esposito A, De Cobelli F, Ironi G, Marra P, Canu T, Mellone R, Del Maschio A. CMR in Assessment of Primary Malignant Tumors. JACC Cardiovasc Imaging 2014;7:1057-61.

48. Liddy S, McQuade C, Walsh KP, Loo B, Buckley O. The Assessment of Cardiac Masses by Cardiac CT and CMR Including Pre-op 3D Reconstruction and Planning. Curr Cardiol Rep 2019;21:103.

49. Perica E, Sun Z. Patient-specific three-dimensional printing for pre-surgical planning in hepatocellular carcinoma treatment. Quant Imaging Med Surg 2017;7:668-77.

50. Witowski J, Wake N, Grochowska A, Sun Z, Budzyński A, Major P, Popiela TJ, Pędziwiatr M. Investigating accuracy of 3D printed liver models with computed tomography. Quant Imaging Med Surg 2019;9:43-52.

51. Sun Z, Liu D. A systematic review of clinical value of three-dimensional printing in renal disease. Quant Imaging Med Surg 2018;8:311-25.

Cite this article as: Li X, Chen Y, Liu J, Xu L, Li Y, Liu D, Sun Z, Wen Z. Cardiac magnetic resonance imaging of primary cardiac tumors. Quant Imaging Med Surg 2020;10(1):294-313. doi: 10.21037/qims.2019.11.13 